\title{
Cytogenetic and molecular predictors of response in patients with myeloid malignancies without del[5q] treated with lenalidomide
}

\author{
Yuka Sugimoto', Mikkael A Sekeres², Hideki Makishima', Fabiola Traina', Valeria Visconte ${ }^{1}$, Anna Jankowska', \\ Andres Jerez ${ }^{1}$, Hadrian Szpurka', Christine L O'Keefe', Kathryn Guinta', Manuel Afable², Ramon Tiu', \\ Kathy L McGraw ${ }^{3}$, Alan F List ${ }^{3}$ and Jaroslaw Maciejewski ${ }^{1,4^{*}}$
}

\begin{abstract}
Background: While lenalidomide (LEN) shows high efficacy in myelodysplastic syndromes (MDS) with del[5q], responses can be also seen in patients presenting without del[5q]. We hypothesized that improved detection of chromosomal abnormalities with new karyotyping tools may better predict response to LEN.

Design and methods: We have studied clinical, molecular and cytogenetic features of 42 patients with MDS, myeloproliferative neoplasms (MPN), MDS/MPN overlap syndromes and secondary acute myeloid leukemia (sAML) without del[5q] by metaphase cytogenetics (MC) who underwent therapy with LEN.

Results: Fluorescence in situ hybridization (FISH) or single nucleotide polymorphism array (SNP-A)-based karyotyping marginally increased the diagnostic yield over MC, detecting 2/42 (4.8\%) additional cases with del[5q], one of whom were responded to LEN. Responses were more often observed in patients with a normal karyotype by MC (60\% vs abnormal MC; $17 \%, p=.08)$ and those with gain of chromosome 8 material by either of all 3 karyotyping methods (83\% vs all other chromosomal abnormalities; $44 \% p=.11$ ). However, 5 out of those 6 patients received combined LEN/AZA therapy and it may also suggest those with gain of chromosome 8 material respond well to AZA. The addition of FISH or SNP-A did not improve the predictive value of normal cytogenetics by MC. Mutational analysis of TET2, UTX, CBL, EZH2, ASXL1, TP53, RAS, IDH1/2, and DNMT-3A was performed on 21 of 41 patients, and revealed 13 mutations in 11 patients, but did not show any molecular markers of responsiveness to LEN.
\end{abstract}

Conclusions: Normal karyotype and gain of chromosome 8 material was predictive of response to LEN in non-del [5q] patients with myeloid malignancies.

Keywords: Lenalidomide, del[5q], Metaphase cytogenetics, Fluorescence in situ hybridization, Single nucleotide polymorphism array

\section{Background}

Lenalidomide (LEN) is particularly effective in patients with myelodysplastic syndromes (MDS) and the del[5q] cytogenetic abnormality [1-3]. In MDS-003, the phase II registration trial of 148 lower-risk MDS patients with del[5q] with or without other karyotypic abnormalities, $67 \%$ achieved transfusion independence with a complete

\footnotetext{
* Correspondence: maciejj@ccf.org

'Department of Translational Hematology and Oncology Research, Cleveland

Clinic Taussig Cancer Institute, Cleveland, OH, USA

Full list of author information is available at the end of the article
}

and partial cytogenetic response rate of $45 \%$ and $28 \%$, respectively [2]. There was no significant association between karyotypic complexity and the frequency of a cytogenetic response. LEN also has activity in a proportion of MDS without del[5q] [4] and [5]. Transfusiondependent MDS patients low- or Int-1 by the International Prognostic Scoring System (IPSS) without del[5q] achieved a $43 \%$ overall rate of hematologic improvement [4]. However, there were no significant differences in the rate of transfusion independence according to age, sex, FAB type, IPSS category, cytogenetic pattern, or

\section{Ciomed Central}


early cytopenias. In higher risk (IPSS; Int-2, high) MDS patients with del[5q] with or without other karyotypic abnormalities, 27\% achieved complete remission (CR), including $67 \%$ of patients with isolated del[5q], vs. $1 / 1$ and $0 / 27$ patients with one or more than one additional chromosomal abnormalities, respectively $(P<.001)$ [3]. Recently, high-dose LEN therapy resulted in a $14 \% \mathrm{CR} /$ partial response (PR) rate in AML patients with del[5q] [6], and a $30 \% \mathrm{CR} /$ complete remission without complete recovery of all blood counts $(\mathrm{CRi})$ rate in older AML patients without del[5q] [5]. To date, the presence of del [5q] with or without additional chromosomal abnormalities detected by metaphase cytogenetics (MC) remains the best prognostic factor for response to LEN. As patients without del[5q] can also show responses to LEN, identification of additional markers of response/ resistance is of utmost importance. Clinically, cytogenetic abnormalities including cryptic deletions of $5 \mathrm{q}$, along with certain other mutations, may constitute additional lesions predictive of response. For instance, the presence of TP53 mutations has been shown to be associated with poor prognosis in azacitidine-treated MDS patients [7], and in LEN-treated MDS or AML patients with del[5q] $[8,9]$.

The diagnostic yield of MC can be enhanced by application of fluorescence in situ hybridization (FISH) for targeted detection of chromosomal lesions including del [5q], as this technique is considered to be more sensitive and allow for detection of smaller clones [10]. Similarly, single nucleotide polymorphism array (SNP-A)-based karyotyping, due to its superb resolution, may allow for detection of previously cryptic unbalanced chromosomal defects [10] and [11]. Both techniques can be performed on interphase cells, and thereby do not require cell division.

In addition to mostly unbalanced cytogenetic defects, mutations of a number of genes, including TET2 [12,13], UTX [14], CBL [15], EZH2 [16-18], ASXL1 [19-21], TP53 [7,22,23], RAS [24,25], IDH1/2 [26], and DNMT3A [27] have been implicated in the pathogenesis of MDS and may also modulate clinical features including responsiveness to LEN.

We examined a cohort of patients without del[5q] treated with LEN and explored the relationship between molecular features and clinical response to LEN.

\section{Methods \\ Patients}

Bone marrow (BM) and/or peripheral blood (PB) were collected from 755 patients with myeloid malignancies seen at Cleveland Clinic (CC) and H. Lee Moffitt Cancer Center between 2002 and 2010. First, a cohort of 122 patients, who were examined with all 3 cytogenetic methods (MC, FISH and SNP-A) on the same sample, was collected. Next, data from 42 patients with MDS (31; RA, 5; RARS, 13; RCMD, 1; RAEB-1, 4; RAEB-2, 7; MDS-U, 1), myeloproliferative neoplasms (MPN) (PMF, 2), MDS/MPN overlap syndrome (7; CMML-1, 2; CMML-2, 2; MDS/MPN-U, 3), or 2 secondary acute myeloid leukemia (sAML) without del[5q], who received LEN for at least 8 weeks, were collected retrospectively. The schedule and dosage of lenalidomide was primarily $10 \mathrm{mg} /$ day ( $5 \mathrm{mg} /$ day in a few cases) for 1-21 days, with a 28-day cycle. All bone marrow biopsies were reviewed and diagnoses confirmed at Cleveland Clinic and H. Lee Moffitt Cancer Center. Response to LEN was defined by the modified International Working Group (IWG) response criteria (2006) [28]. Informed consent for sample and clinical information collection was obtained according to protocols approved by the Cleveland Clinic or the H. Lee Moffitt Cancer Center IRBs.

\section{Cytogenetic analysis}

Cytogenetic analysis was performed on marrow aspirates and/or peripheral blood, in cases where bone marrow samples could not be obtained, according to standard methods (Figure 1). 20 metaphase spreads were examined per patient, if available. Chromosome preparations were G-banded using trypsin and Giemsa (GTG) and karyotypes were described according to ISCN [29].

\section{Fluorescence in situ hybridization}

FISH analysis was performed on cell pellets from unstimulated cytogenetic cultures. Thresholds for interpretation as a positive result were established for each probe at 3 standard deviations above the mean of 20 normal bone marrow samples. In 27 cases, FISH analysis was performed at an outside reference laboratory (Mayo Clinic) using the following dual color probe sets: $5 \mathrm{p} 15.2$ (normal range; 0-4\%)/EGR1 (5q31) (0-6\%), CEP7 (0-5\%)/ 7q31 (0-7\%), CEP8 (0-2\%)/MYC (8q24) $(0-2 \%)$ and 20q12 (0-5\%)/20qter (0-5\%). In 95 cases, FISH was performed at $\mathrm{CC}$ using three dual color probe sets (Abbott Molecular, Abbott Park, IL). The first probe set consisted of D5S23 and D5S721 (5p15.2) labeled in Spectrum Green (0-6\%) and EGR1 (5q31) labeled in Spectrum Orange $(0-6 \%)$. The second probe set consisted of the chromosome 7 centromere labeled in Spectrum Green $(0-5 \%)$ and D7S486 (7q31) labeled in Spectrum Orange (0-7\%). The third probe set consisted of the chromosome 8 centromere labeled in Spectrum Green $(0-8 \%)$ and D20S108 (20q12) labeled in Spectrum Orange (0-4\%).

\section{DNA extraction}

DNA was extracted from whole bone marrow using the ArchivePure Kit (5Prime, Gaithersburg, MD) per manufacturer's instructions. The concentration of the DNA was obtained using a ND-1000 spectrophotometer 


\section{A Chromosome 5 Normal}

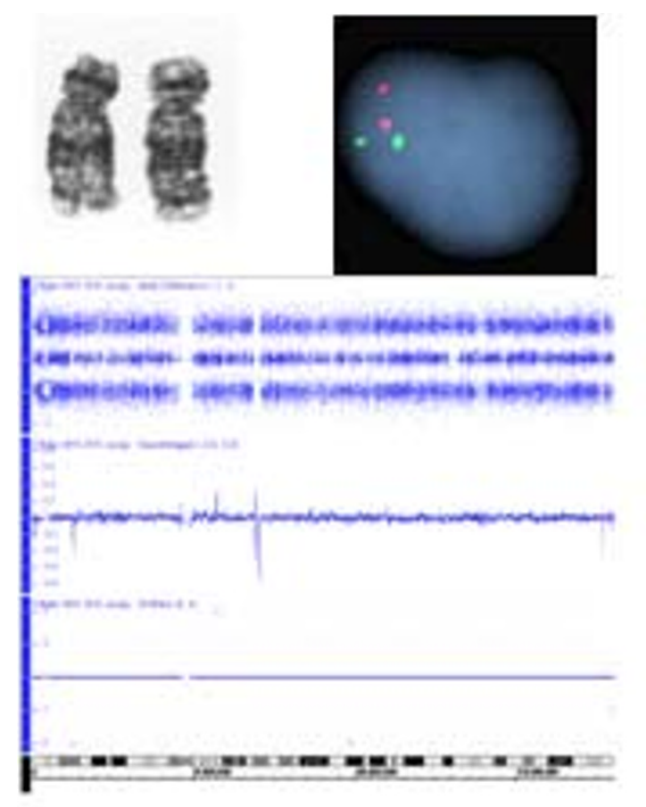

B Chromosome 5q Deletion

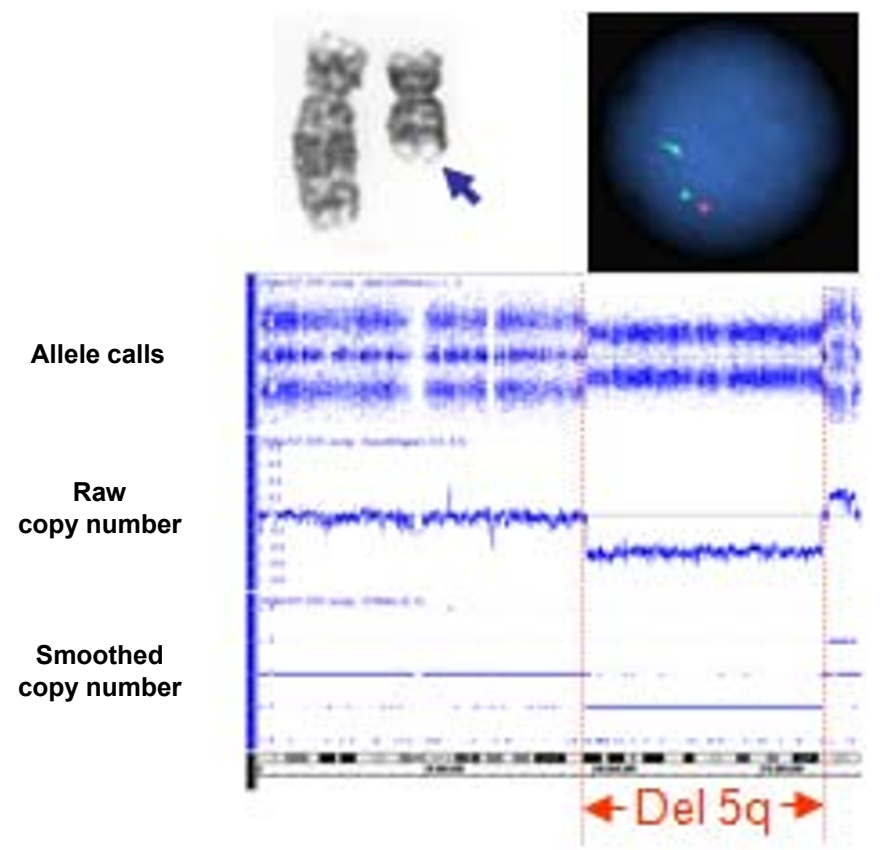

Figure 1 Detection of chromosome 5 abnormalities by different cytogenetic techniques. Examples of normal chromosome 5 (A) and deleted chromosome 5 (B) are presented. The deleted lesion is denoted by a shorter chromosome in MC (top left panel, blue arrow), a single red signal in FISH (top right panel) and segmental copy number loss in the SNP-A karyotype (bottom panel).

(NanoDrop, Wilmington, DE, USA). To study the germ line, T lymphocytes (CD3+) were isolated using RoboSep according to manufacturer's protocol (StemCell Technologies, Vancouver, BC, Canada).

\section{Mutational analysis}

Mutation screening was performed for genes known to be mutated in myeloid malignancies (TET2, UTX, CBL, EZH2, ASXL1, TP53, RAS, IDH1/2, and DNMT3A) in the cases for which DNA was available $(\mathrm{N}=21)$. All of the coding exons for TET2, UTX, EZH2 and TP53 were screened as previously reported [13-17] and [23]. Direct genomic sequencing of exons 8 and 9 of $C B L$, exon 12 of $A S X L-1$, exons 1 and 2 of $N-R A S$ and $K-R A S$, exon 4 of $I D H-1$ and $I D H-2$, and exon 23 of DNMT3A was performed as previously described $[15,21,26,27,30]$. The reference sequence from UCSC Genome Browser was used to identify the position of each amino acid change listed in Table 1 (TET2, uc003hxk.2; EZH2, uc003wfb.1; ASXL-1, uc002wxs.1; KRAS, uc001rgp.1; DNMT-3, uc002rgc.1). In selected cases CD3+ cells were purified and used as controls to confirm the somatic status of mutations.

\section{SNP-A cytogenetics}

Affymetrix Gene Chip Mapping $250 \mathrm{~K}$ Assay Kit or Genome-Wide Human SNP Assay Kit 6.0 (Affymetrix,
Santa Clara, CA) was used for analysis of 52 and 70 samples with myeloid malignancies, respectively. Following Nsp I digestion (New England Biolabs, Ipswich, MA), fragmented DNA was ligated to adaptor using T4 ligase (New England Biolabs) followed by PCR amplification. The PCR product was hybridized to the array, processed with the Fluidic Station 450 and scanned using the Gene Chip Scanner 3000 (Affymetrix).

\section{Biostatistical evaluation of SNP-A data}

GeneChip Mapping $250 \mathrm{~K}$ Array data, signal intensity and SNP calls were determined using Gene Chip Genotyping Analysis Software Version 4.0 (GTYPE). Copy number and $\mathrm{LOH}$ were investigated using Copy Number Analyzer for Affymetrix GeneChip Mapping (CNAG v. 3.0). For Genome-Wide Human SNP Array 6.0, the genotype calls for each individual were determined by the Birdseed version 1 genotype-calling algorithm, embedded in the software included with the Affymetrix Genotyping Console 2.0 (Affymetrix).

For detection of lesions we used the following diagnostic algorithm: lesions identified by SNP-A were compared with the Database of Genomic Variants (http:// projects.tcag.ca/variation/) and our own internal control series to exclude known copy number variants (CNVs). In our internal control cohort, the largest area of copy 
Table 1 Mutation analysis in the cohort of LEN patients

\begin{tabular}{|c|c|c|c|c|c|c|c|c|c|c|c|c|}
\hline Case & Response & TET2 & UTX & $C B L$ & $E Z H 2$ & ASXL1 & TP53 & $N-R A S$ & K-RAS & IDH1 & IDH2 & DNMT3A \\
\hline 1 & $C R$ & WT & WT & WT & WT & WT & WT & WT & WT & WT & WT & WT \\
\hline 2 & $C R$ & WT & WT & WT & WT & L775fsX1 & WT & WT & WT & WT & WT & WT \\
\hline 3 & PR & WT & WT & WT & WT & WT & WT & WT & WT & WT & WT & WT \\
\hline 4 & NR & WT & WT & WT & WT & WT & WT & WT & WT & WT & WT & WT \\
\hline 5 & $C R$ & WT & WT & WT & WT & E1102D & WT & WT & WT & WT & WT & $\mathrm{R} 882 \mathrm{H}$ \\
\hline 6 & PR & P1681fsX2 & WT & WT & WT & $P 1277 f s X 2$ & WT & WT & WT & WT & WT & WT \\
\hline 7 & $C R$ & WT & WT & WT & WT & WT & WT & WT & WT & WT & WT & WT \\
\hline 8 & $\mathrm{HI}$ & WT & WT & WT & WT & WT & WT & WT & WT & WT & WT & WT \\
\hline 10 & $C R$ & WT & WT & WT & WT & WT & $W T$ & WT & WT & WT & WT & WT \\
\hline 11 & $\mathrm{HI}$ & WT & WT & WT & WT & WT & WT & WT & L19F & WT & WT & WT \\
\hline 12 & $C R$ & V1417F & WT & WT & WT & WT & WT & WT & WT & $W T$ & $W T$ & WT \\
\hline 13 & NR & WT & WT & WT & WT & WT & WT & WT & WT & WT & WT & WT \\
\hline 14 & $P R$ & WT & WT & WT & WT & WT & $W T$ & WT & WT & WT & WT & WT \\
\hline 15 & $C R$ & T1978P & WT & WT & WT & WT & WT & WT & WT & WT & WT & WT \\
\hline 16 & NR & WT & WT & WT & WT & $\mathrm{S} 846 \mathrm{~N}$ & WT & WT & WT & WT & WT & WT \\
\hline 17 & NR & N1068fsX13 & WT & WT & WT & WT & WT & WT & WT & WT & WT & WT \\
\hline 18 & NR & WT & WT & WT & WT & WT & WT & WT & WT & WT & WT & WT \\
\hline 19 & NR & P1962L & WT & WT & WT & WT & WT & WT & WT & WT & WT & WT \\
\hline 20 & $C R$ & WT & WT & WT & WT & WT & WT & WT & WT & WT & WT & $\mathrm{R} 882 \mathrm{H}$ \\
\hline 21 & $\mathrm{HI}$ & WT & WT & WT & T726X & WT & WT & WT & WT & WT & WT & WT \\
\hline 22 & $\mathrm{HI}$ & WT & WT & WT & WT & WT & WT & WT & WT & WT & WT & WT \\
\hline
\end{tabular}

Abbreviation: $C R$ complete response; $P R$ partial response; $H I$ hematologic improvement; $W T$ wild type

neutral loss of heterozygosity $(\mathrm{CN}-\mathrm{LOH})$ we observed was $52.5 \mathrm{Mb}$ and the average size of $\mathrm{CN}-\mathrm{LOH}$ was 7.2 $\mathrm{Mb}$. In addition, we observed that areas of $\mathrm{LOH}$ in controls were exclusively interstitial. Consequently, areas of $\mathrm{LOH}<24.8 \mathrm{Mb}$ (mean size $\pm 2 \mathrm{SD}$ ) were excluded from analysis in the patient set. Deletions and gains of chromosomal material seen on metaphase karyograms and SNP-A samples that showed a concordantly normal karyotype by both MC and SNP-A testing were not further confirmed. When possible, all other remaining new defects were confirmed using paired analysis of CD3+ cells.

\section{Statistical analysis}

Demographic and baseline MDS disease characteristics of all patients were summarized descriptively, using medians and ranges. The response differences between 2 groups were compared using Fisher's exact test, with a two-sided alpha value of .05 denoting significance.

\section{Results}

\section{Comparison between metaphase cytogenetics and other} cytogenetic methods

We first identified a cohort of 122 patients for whom $\mathrm{MC}$, FISH and SNP-A analyses were performed on the same sample, to evaluate the additional yield of more sensitive techniques for identifying del[5q]. In patients with MDS $(\mathrm{N}=82)$, MDS/MPN $(\mathrm{N}=13)$, AML $(\mathrm{N}=$
23), and MPN (N = 4), the detection rate of $\operatorname{del}[5 \mathrm{q}]$ increased only marginally with the use of additional techniques, from $24 \%(\mathrm{MC}+\mathrm{FISH})$, to $25 \%(\mathrm{MC}+$ SNP-A), 25\% (FISH + SNP-A) and 26\% (all 3 methods) (Figure 1, Table 2). We also identified 3 cases with copy neutral loss of heterozygosity $(\mathrm{CN}-\mathrm{LOH})$ of $5 \mathrm{q}$ in this cohort using SNP-A. One region of $\mathrm{CN}-\mathrm{LOH}$ was found in SAML with complex chromosomal abnormalities including del[5][q13q33] by $\mathrm{MC}$, and the other $2 \mathrm{CN}$ $\mathrm{LOH}$ regions were detected in MDS cases with chromosomal abnormalities other than del[5q].

\section{Clinical characteristics of non-del[5q] patients who had LEN therapy}

Clinical characteristics of the patients with myeloid malignancies without del[5q] by $\mathrm{MC}$ and who received LEN are summarized in Table 3; 31 patients received LEN monotherapy (complete response [CR], $\mathrm{N}=3$;

Table 2 Number and percentage of del[5q] detected using metaphase cytogenetics, FISH and SNP-A alone or in combination in myeloid malignancies $(\mathrm{N}=122)$

\begin{tabular}{lccccccc}
\hline & MC & FISH & SNP & $\begin{array}{c}\text { MC } \\
\text { +FISH }\end{array}$ & $\begin{array}{c}\text { MC } \\
\text { +SNP }\end{array}$ & $\begin{array}{c}\text { FISH } \\
\text { +SNP }\end{array}$ & $\begin{array}{c}\text { MC+FISH } \\
\text { +SNP }\end{array}$ \\
\hline Number & 24 & 27 & 25 & 29 & 30 & 31 & 32 \\
Percentage & $20 \%$ & $22 \%$ & $21 \%$ & $24 \%$ & $25 \%$ & $25 \%$ & $26 \%$ \\
\hline
\end{tabular}

MC metaphase cytogenetics; FISH fluorescence in situ hybridization; SNP single nucleotide polymorphism array-based karyotyping. 
Table 3 Summary of clinical characteristics of patients without del[5q] on MC who received lenalidomide $(\mathrm{N}=42)$

\begin{tabular}{|c|c|c|c|}
\hline \multicolumn{4}{|c|}{ Diagnosis (No. of Patients) } \\
\hline \multirow[t]{7}{*}{ MDS } & & 31 & \\
\hline & RA & & 5 \\
\hline & RARS & & 13 \\
\hline & $\mathrm{RCMD}$ & & 1 \\
\hline & RAEB-1 & & 4 \\
\hline & RAEB-2 & & 7 \\
\hline & MDS-U & & \\
\hline \multirow[t]{4}{*}{ MDS/MPN } & & 7 & \\
\hline & CMML-1 & & 2 \\
\hline & CMML-2 & & 2 \\
\hline & MDS/MPN-U & & 3 \\
\hline PMF & & 2 & \\
\hline SAML & & 2 & \\
\hline \multicolumn{4}{|c|}{ Age (years old) } \\
\hline & Median (Range) & & $70(46-83)$ \\
\hline \multicolumn{4}{|c|}{ Sex (No. of Patients) } \\
\hline & M & & 28 \\
\hline & $\mathrm{F}$ & & 14 \\
\hline \multicolumn{4}{|c|}{ IPSS (No. of Patients) } \\
\hline & LOW & & 12 \\
\hline & INT-1 & & 11 \\
\hline & INT-2 & & 7 \\
\hline & $\mathrm{HIGH}$ & & 1 \\
\hline & not indicated & & 11 \\
\hline
\end{tabular}

Duration of MDS (months)

Median (Range)

Previous Therapies

$\begin{array}{ll}\text { Yes } & 27\end{array}$

No $\quad 15$

Transfusion dependence (No. of Patients)

Yes $\quad 30$

No 12

Neutropenia $\left(<1.5 \times 10^{9} / \mu\right)$ (No. of Patients)

Yes 5

No $\quad 37$

Thrombocytopenia $\left(<100 \times 10^{9}\right)$ (No. of Patients)

Yes 12

No $\quad 30$

Therapy (No. of Patients)

LEN (5-10 mg/day) alone

LEN high dose (50 mg/day)

LEN/AZA

Duration of LEN therapy (months)

Response to therapy (No. of Patients)

$\begin{array}{lr}C R & 9 \\ P R & 3 \\ H I & 10 \\ N R & 16 \\ N E & 4\end{array}$

Abbreviation: MDS myelodysplastic syndromes; $R A$ refractory anemia; $R A R S$ refractory anemia with ring sideroblasts; $R C M D$ refractory cytopenia with multilineage dysplasia; RAEB refractory anemia with excess blasts, MDS-U MDS unclassifiable; MDS/MPN MDS/myeloproliferative neoplasm; CMML chronic myelomonocytic leukemia; MDS/MPN-U MDS/MPN unclassifiable; PMF primary myelofibrosis; $S A M L$ secondary acute myeloid leukemia; $M$ male; $F$ female; $L E N$ lenalidomide; $L E N / A Z A$ LEN/azacitidine; $C R$ complete response; $P R$ partial response; $H I$ hematological improvement; $N R$ no response; $N E$ not evaluated. 
partial response $[\mathrm{PR}], \mathrm{N}=2$; hematologic improvement $[\mathrm{HI}], \mathrm{N}=9$; no response [NR], $\mathrm{n}=13$; not evaluated [NE], $\mathrm{n}=4$ ), and 11 patients received LEN/azacitidine (AZA) combination therapy $(\mathrm{CR}, \mathrm{N}=6$; $\mathrm{PR}, \mathrm{N}=1$; $\mathrm{HI}$, $\mathrm{N}=1$; $\mathrm{NR}, \mathrm{N}=3$ ). Only 1 patient had past history of Hodgkin's lymphoma and was suspected to have therapy-related MDS/MPN.

By MC, 32 patients (76\%) who received treatment with LEN showed a normal karyotype, 1 patient (2.4\%) had no growth to their bone marrow sample, and 9 (21\%) had an abnormal karyotype other than del[5q] (Table 4). However, the frequency of an abnormal karyotype was increased to $67 \%$ using FISH and SNP-A as karyotyping tools in patients receiving LEN without del[5q] by MC (Figure 2). Previously cryptic del[5q] was detected by both SNP-A and FISH in an additional $1 / 18$ patients with normal MC (Case 19 in Table 4). $\operatorname{Del}[5 \mathrm{q}]$ was also revealed by FISH in 1 patient with unsuccessful MC (Case 14 in Table 4), but, due to the small size of the clone (8\%), SNP-A was not able to detect this lesion.

\section{Impact of chromosomal abnormalities on response}

In 27 patients who received LEN for more than 2 months, the overall response rate (ORR) was $52 \%$, including 3 CR, 2 PR and 9 HI. Case 19, who was diagnosed as sAML with del[5q] by FISH and SNP-A only, was refractory to high-dose LEN. Case 14, a MDS/MPN unclassifiable (MDS/MPN-U) patient in whom a del[5q] clone was detected only by FISH due to the small size, had a sustained PR with transfusion independence. The ORR to LEN in patients with normal MC was $60 \%$, vs. $17 \%$ for those with chromosomal aberrations by $\mathrm{MC}(p$ $=.08$ ); the addition of FISH or SNP-A did not improve the predictive value of normal cytogenetics (Table 5). We also analyzed 11 patients without del[5q] by MC who received combination therapy with AZA and LEN, for whom the ORR was 73\% (6 CR, 1 PR, $1 \mathrm{HI}$ ). By MC, $8 / 11$ patients had a normal karyogram and a response of $75 \%$, compared to 3 patients with chromosomal lesions, 1 of whom did not respond. Similar to the results with LEN alone, inclusion of defects detected by SNP-A or FISH did not allow for better separation of responders based on normal cytogenetics by MC. The most frequent cytogenetic abnormality among the patients who received LEN was gain of chromosome 8 material (6/42), followed by the loss of chromosome 20 material (5/42). Patients with gain of chromosome 8 had high ORR to LEN (5 out of $6,83 \%$ ) and ORR in patients with chromosome 20 abnormalities was 3 out of 5 . The response of patients with all other chromosomal abnormalities by MC, FISH or SNP-A was $44 \%$. These findings indicate that responses tend to be more often observed in patients with gain of chromosome 8 material by either of all 3 karyotyping methods ( $p=$ .11 ), although 5 out of those 6 patients received combined LEN/AZA therapy.

\section{Impact of mutational status on response}

In 21 LEN-treated patients (11 patients with LEN only and 10 patients with LEN/AZA), somatic mutations were found in TET2 $(\mathrm{N}=5), E Z H 2(\mathrm{~N}=1), A S X L 1(\mathrm{~N}$ $=4), K-R A S(\mathrm{~N}=1)$, and DNMT3A $(\mathrm{N}=2)$ in 11 patients. ASXL1 and DNMT3, or TET2 and ASXL1 mutations were each found in one patient, and each of these patients achieved CR with LEN/AZA or PR with LEN only. ORR was $73 \%$ in patients with any of investigated mutations and $70 \%$ in patients without a mutation $(p=.36)$. For patients treated with LEN only, 3 out of 8 (38\%) responders had mutations, and 1 out of 3 (33\%) non-responders harbored mutations.

\section{Discussion}

Though the mechanism of action of lenalidomide has not been definitively determined, it purportedly works through inhibition of phosphatase activity in the common deleted region (CDR) of $5 \mathrm{q}$ that plays a key role in cell cycle regulation, through a defect in ribosomal protein function, via direct cytotoxic mechanisms in patients with the del (5q) cytogenetic abnormality, and supposedly through effects on the bone marrow microenvironment in patients who do not have this lesion, via abrogation of the effects of pro-apoptotic, pro-inflammatory cytokines [1-3]. Until now, additional markers of responsiveness to LEN beyond del[5q] have not been identified.

New cytogenetic tools such as FISH and SNP-A are likely to improve the diagnostic value of cytogenetic diagnostics $[8,9,29]$. We first assumed that we would detect previously unrecognized cases of del[5q] using these techniques. In our cohort of patients given LEN, del[5q] cases detected by FISH and/or SNP-A ranged from 2 out of all 42 cases (4.8\%) of patients without del [5q] by MC, and 1 out of 32 cases (3.1\%) with normal MC. These frequencies are similar to those reported in a previous study, in which $5.96 \%$ of cases without del [5q] by $\mathrm{MC}$ and $2.7 \%$ of those with normal karyotype by MC were found to be del[5q] by FISH [31]. These results suggest that FISH and SNP-A may marginally improve the detection rate of del[5q]. While the detection rate of cryptic del[5q] was only marginally enhanced with FISH and SNP-A, new karyotyping tools improved the detection rate of other chromosomal abnormalities in our cohort from $21 \%$ to $67 \%$ compared to MC. A previous study of 43 MDS patients suggested that the cytogenetic pattern correlates with hematologic response; 10 of 12 patients (83\%) with del[ $5 \mathrm{q}]$ achieved sustained red blood cell transfusion independence, 
Table 4 Patients characteristics who received LEN without del[5q] by MC $(N=42)$

\begin{tabular}{|c|c|c|c|c|c|c|c|c|c|c|c|}
\hline Case & $\begin{array}{l}\text { Age } \\
\text { (y.o.) }\end{array}$ & Sex & Diagnosis & IPSS & Therapy & Response & MC & FISH & $\begin{array}{l}\text { SNP- } \\
\text { A }\end{array}$ & & \\
\hline 1 & 73 & $M$ & RAEB-2 & INT-2 & LEN/AZA & $C R$ & $\mathrm{~N}$ & $\mathrm{~N}$ & & Gain & $4 q 13.2$ \\
\hline \multirow[t]{2}{*}{2} & 75 & M & RAEB-1 & INT-1 & LEN/AZA & $C R$ & $\mathrm{~N}$ & $\begin{array}{l}\text { trisomy } \\
8\end{array}$ & $9 \%$ & Gain & $8 q 11.1 q 11.21$ \\
\hline & & & & & & & & & & UPD & $11 q 14.1 q 21$ \\
\hline \multirow[t]{2}{*}{3} & 62 & M & $\begin{array}{l}\text { MDS/MP } \\
\mathrm{N}-U\end{array}$ & INT-1 & LEN/AZA & $P R$ & N & N & & UPD & 1 pterp32.3 \\
\hline & & & & & & & & & & UPD & 3p21.31p21.1 \\
\hline \multirow[t]{12}{*}{4} & 68 & M & RAEB-2 & $\mathrm{HIGH}$ & LEN/AZA & NR & $\begin{array}{l}\text { complex karyotype, including trisomy 8, del } \\
{[7 q] \text {, del[12], and del[20] }}\end{array}$ & del[7q] & $68 \%$ & Gain & 8 \\
\hline & & & & & & & & del[20q] & $60 \%$ & Loss & $11 p 14.3 p 13$ \\
\hline & & & & & & & & $\begin{array}{l}\text { trisomy } \\
8\end{array}$ & $41 \%$ & Loss & 12p12.3p11.21 \\
\hline & & & & & & & & & & Loss & $12 q 21.1 q 21.31$ \\
\hline & & & & & & & & & & Loss & $16 q 22.3 q 24.3$ \\
\hline & & & & & & & & & & Loss & 1p22.2p22.1 \\
\hline & & & & & & & & & & Loss & $20 \mathrm{q} 11.2 \mathrm{q} 13.33$ \\
\hline & & & & & & & & & & Loss & $21 q 11.2 q 21.1$ \\
\hline & & & & & & & & & & Loss & $2 q 31.3 q 32.1$ \\
\hline & & & & & & & & & & Loss & $6 q 23.3$ \\
\hline & & & & & & & & & & Gain & $7 q 11.21 q 11.22$ \\
\hline & & & & & & & & & & Loss & $7 q 22.1 q 36.2$ \\
\hline \multirow[t]{3}{*}{5} & 68 & M & RAEB-2 & INT-2 & LEN/AZA & $C R$ & $47, X Y,+8[6]$ & $\begin{array}{l}\text { trisomy } \\
8\end{array}$ & $9 \%$ & Gain & $14 q 11.1 q 11.2$ \\
\hline & & & & & & & & & & UPD & 19p13.11p12 \\
\hline & & & & & & & & & & Gain & $8 p 23.3 q 24.3$ \\
\hline 6 & 73 & M & CMML-1 & $\mathrm{NE}$ & LEN & $P R$ & $\mathrm{~N}$ & del[20q] & $10 \%$ & UPD & 9pterp22.2 \\
\hline 7 & 67 & M & PMF & NE & LEN & $P R$ & N & N & & Loss & $11 q 23.3$ \\
\hline 8 & 66 & M & RCMD & LOW & LEN & $\mathrm{HI}$ & $46, X Y$,del(20)(q11q13)[2]/4 6,XY[18] & del[20q] & $17 \%$ & Gain & $8 q 11.1 q 11.23$ \\
\hline 9 & 69 & M & RAEB-1 & INT-2 & LEN/AZA & $C R$ & N & N & & $\mathrm{NE}$ & \\
\hline 10 & 64 & M & $\begin{array}{l}\text { MDS/MP } \\
\mathrm{N}-\mathrm{U}\end{array}$ & NE & LEN & $C R$ & $\mathrm{~N}$ & $\mathrm{~N}$ & & N & \\
\hline 11 & 79 & $\mathrm{~F}$ & CMML-2 & NE & LEN/AZA & $\mathrm{HI}$ & $47, X X,+8[20]$ & $\begin{array}{l}\text { trisomy } \\
8\end{array}$ & $42 \%$ & Gain & 8 \\
\hline 12 & 62 & $\mathrm{~F}$ & RAEB-2 & INT-2 & LEN/AZA & $C R$ & N & N & & N & \\
\hline \multirow[t]{3}{*}{13} & 62 & $\mathrm{~F}$ & RARS & INT-1 & LEN & NR & $\begin{array}{c}\text { 46,XX,add(15)(p11.1),add(2 2)(p11.2)[3]/47, } \\
\text { idem,+19[19]. }\end{array}$ & del[7q] & $11 \%$ & Gain & 19 \\
\hline & & & & & & & & del[7] & $6 \%$ & Gain & $3 q 26.1$ \\
\hline & & & & & & & & & & Gain & $4 p 16.2$ \\
\hline \multirow[t]{4}{*}{14} & 72 & M & $\begin{array}{l}\text { MDS/ } \\
\text { MPN-U }\end{array}$ & INT-2 & LEN & PR & no growth & del[5q] & $8 \%$ & Loss & $20 q 11.1 q 13.12$ \\
\hline & & & & & & & & del[20q] & $35 \%$ & Loss & $2 p 21 p 24.1$ \\
\hline & & & & & & & & & & Loss & $8 q 11.23 q 12.1$ \\
\hline & & & & & & & & & & Gain & 9p12pter \\
\hline \multirow[t]{2}{*}{15} & 63 & M & RAEB-2 & $\mathrm{NE}$ & LEN/AZA & $C R$ & $\mathrm{~N}$ & $\mathrm{~N}$ & & Gain & $12 q 24.32$ \\
\hline & & & & & & & & & & Gain & $8 q 11.1$ \\
\hline 16 & 81 & $\mathrm{~F}$ & RAEB-2 & INT-2 & LEN/AZA & NR & $N$ & $N$ & & N & \\
\hline 17 & 69 & M & CMML-2 & - & LEN/AZA & NR & N & NE & & Loss & $2 p 22.3$ \\
\hline \multirow[t]{2}{*}{18} & 46 & M & PMF & - & LEN & NR & $\begin{array}{c}\text { balanced translocation at chromosomes } 2 \\
\text { and } 22\end{array}$ & NE & & UPD & $14 q 31.3 q 32.33$ \\
\hline & & & & & & & & & & Gain & $9 p 24.3 p 11.1$ \\
\hline 19 & 70 & $\mathrm{~F}$ & SAML & - & $\begin{array}{l}\text { LEN (High } \\
\quad \text { dose) }\end{array}$ & NR & N & del[5q] & $33 \%$ & Loss & $5 q 31.2$ \\
\hline 20 & 65 & $\mathrm{~F}$ & RARS & LOW & LEN & $C R$ & N & NE & & $\mathrm{N}$ & \\
\hline
\end{tabular}


Table 4 Patients characteristics who received LEN without del[5q] by $\mathrm{MC}(\mathbf{N}=\mathbf{4 2})$ (Continued)

\begin{tabular}{|c|c|c|c|c|c|c|c|c|c|c|c|}
\hline 21 & 70 & $M$ & CMML-1 & INT-1 & LEN & $\mathrm{HI}$ & $N$ & $\mathrm{~N}$ & & UPD & 7q22.1qter \\
\hline 22 & 83 & M & RARS & LOW & LEN & $\mathrm{HI}$ & $N$ & $N$ & & $N$ & \\
\hline 23 & 83 & M & RARS & INT-1 & LEN & NR & N & $N E$ & & $N$ & \\
\hline 24 & 71 & M & MDS-U & INT-1 & LEN & $N E$ & $N$ & $\mathrm{NE}$ & & Loss & $15 q 14$ \\
\hline 25 & 69 & M & RARS & LOW & LEN & NR & $N$ & $\mathrm{NE}$ & & $N$ & \\
\hline 26 & 76 & M & RA & INT-1 & LEN & $N R$ & $N$ & $\mathrm{NE}$ & & Loss & $3 p 22.3$ \\
\hline \multirow[t]{3}{*}{27} & 68 & M & RA & INT-1 & LEN & NR & N & $\mathrm{NE}$ & & Loss & $21 q 21.2$ \\
\hline & & & & & & & & & & Gain & $3 p 14.1$ \\
\hline & & & & & & & & & & Loss & $11 q 14.3$ \\
\hline 28 & 59 & M & RARS & LOW & LEN & NR & $N$ & $N E$ & & $N$ & \\
\hline 29 & 73 & $\mathrm{~F}$ & RA & LOW & LEN & NR & $N$ & NE & & $N$ & \\
\hline 30 & 78 & $\mathrm{~F}$ & RARS & LOW & LEN & $\mathrm{NE}$ & $N$ & $\mathrm{NE}$ & & UPD & 3q21.3qter \\
\hline 31 & 78 & M & RAEB-1 & INT-2 & LEN & NR & $47, X Y,+19$ & $\mathrm{NE}$ & & Gain & 19 \\
\hline \multirow[t]{2}{*}{32} & 80 & M & RAEB-1 & INT-1 & LEN & $\mathrm{NE}$ & $N$ & $\mathrm{NE}$ & & Loss & $17 q 11.2$ \\
\hline & & & & & & & & & & UPD & 8p11.2qter \\
\hline 33 & 79 & $\mathrm{~F}$ & RARS & INT-1 & LEN & $\mathrm{HI}$ & $N$ & $\mathrm{NE}$ & & $N$ & \\
\hline 34 & 73 & $\mathrm{~F}$ & RARS & LOW & LEN & $\mathrm{HI}$ & $N$ & $\mathrm{NE}$ & & Loss & $18 p 11.32$ \\
\hline 35 & 78 & $\mathrm{~F}$ & SAML & - & LEN & $N R$ & $46, X X, t(3 ; 3)$ & $\mathrm{NE}$ & & Loss & $3 q 26.1$ \\
\hline 36 & 80 & M & RAEB-2 & INT-2 & LEN & NR & $N$ & $\mathrm{NE}$ & & Loss & $22 q 13.2$ \\
\hline 37 & 69 & M & RARS & LOW & LEN & $\mathrm{HI}$ & $N$ & $\mathrm{NE}$ & & $N$ & \\
\hline 38 & 59 & $\mathrm{~F}$ & RA & LOW & LEN & $\mathrm{HI}$ & $N$ & $\mathrm{NE}$ & & $N$ & \\
\hline 39 & 62 & $\mathrm{~F}$ & RARS & LOW & LEN & $\mathrm{NE}$ & $N$ & NE & & Gain & $6 p 21.32$ \\
\hline 40 & 82 & M & RARS & INT-1 & LEN & NR & $46, X Y$,del(20)(q11.2) & NE & & Loss & $20 q 11.2 q 13.2$ \\
\hline 41 & 53 & M & RARS & LOW & LEN & $\mathrm{HI}$ & N & NE & $N$ & & \\
\hline \multirow[t]{2}{*}{42} & 56 & $\mathrm{~F}$ & RA & INT-1 & LEN & $\mathrm{HI}$ & $N$ & $\mathrm{NE}$ & & Loss & $9 p 21.2$ \\
\hline & & & & & & & & & & Gain & $1 \mathrm{p} 21.1$ \\
\hline
\end{tabular}

Abbreviation: $M$ male; $F$ female; RAEB refractory anemia with excess blasts; MDS/MPN-U myelodysplastic syndromes/myeloproliferative neoplasm, unclassifiable; $C M M L$ chronic myelomonocytic leukemia; $P M F$ primary myelofibrosis; $R C M D$ refractory cytopenias with multilineage dysplasia; $R A R S$ refractory anemia with ring sideroblasts; $S A M L$ secondary acute myeloid leukemia; MDS-U, MDS unclassifiable; RA refractory anemia; $L E N$ lenalidomide; $A Z A$ azacitidine; $N$ normal; UPD uniparental disomy; NE not evaluated.

compared with $57 \%$ of those with a normal karyotype and $12 \%$ of those with other karyotypic abnormalities $[1,32]$. Consequently, we hypothesized that improved detection of chromosomal abnormalities may better predict poor response to LEN. However, when more abnormalities were found using additional methods, no correlation with response to LEN or LEN/AZA therapy was detected.

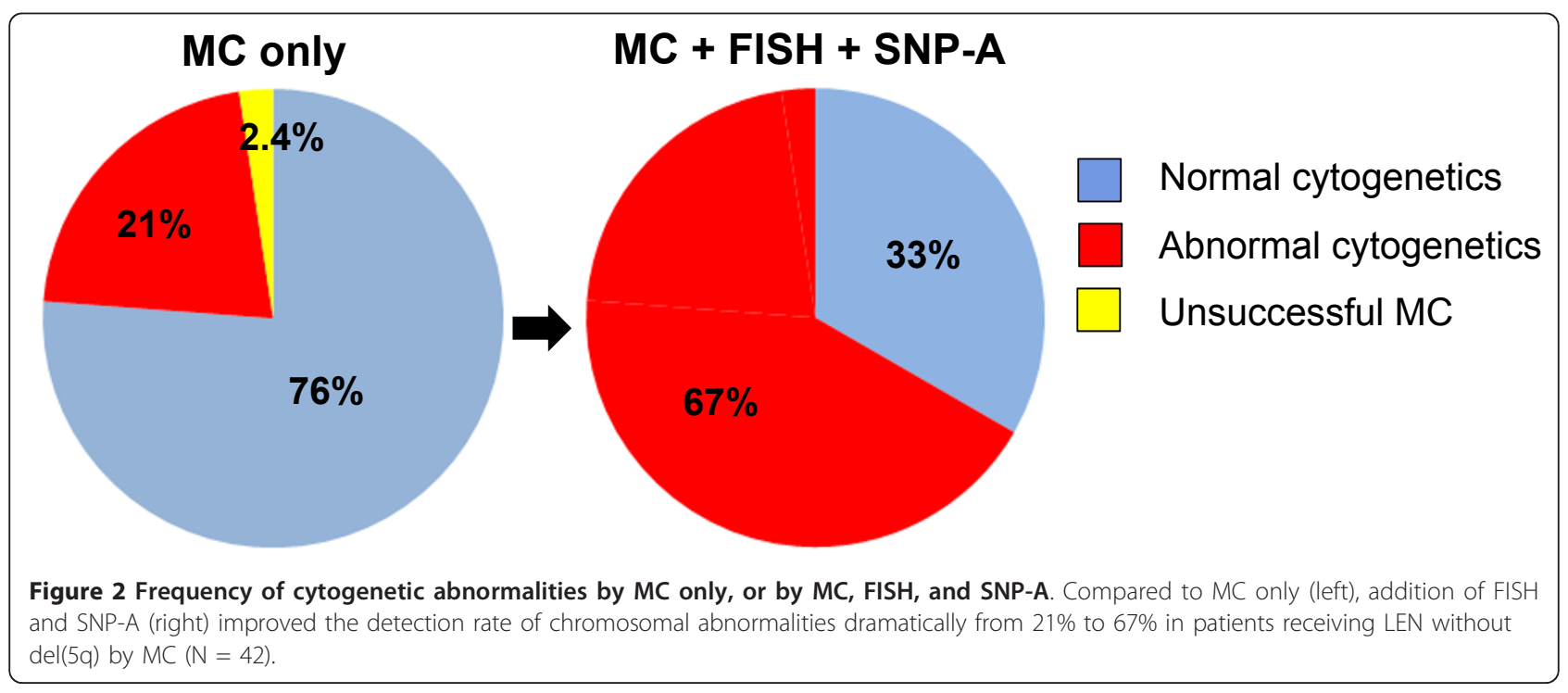


Table 5 Cytogenetic categories and response to therapy in the cohort of LEN patients

\begin{tabular}{|c|c|c|c|}
\hline \multicolumn{4}{|c|}{ A. All patient who received LEN for more than 3 months $(N=38)$} \\
\hline & Normal cytogenetic group & Abnormal cytogenetic group & $\mathrm{p}$ value \\
\hline Categorized by MC only & $64 \%$ & $33 \%$ & 0.07 \\
\hline Categorized by MC/FISH/SNP-A & $64 \%$ & $54 \%$ & 0.4 \\
\hline \multicolumn{4}{|c|}{ B. Monotherapy (LEN only) patients ( $\mathrm{N}=27$ ) } \\
\hline & Normal cytogenetic group & Abnormal cytogenetic group & $\mathrm{p}$ value \\
\hline Categorized by $\mathrm{MC}$ & $60 \%$ & $17 \%$ & 0.08 \\
\hline \multicolumn{4}{|l|}{ only } \\
\hline Categorized by MC/FISH/SNP-A & $64 \%$ & $44 \%$ & 0.27 \\
\hline \multicolumn{4}{|c|}{ C. Patients with combination therapy of AZA + LEN $(N=11)$} \\
\hline & Normal cytogenetic group & Abnormal cytogenetic group & $\mathrm{p}$ value \\
\hline Categorized by MC only & $75 \%$ & $67 \%$ & 0.85 \\
\hline Categorized by MC/FISH/SNP-A & $67 \%$ & $75 \%$ & 0.85 \\
\hline
\end{tabular}

LEN lenalidomide; MC metaphase cytogenetics; FISH fluorescence in situ hybridization; SNP-A single nucleotide polymorphism array karyotyping; $A Z A$ azacitidine.

We also speculated that we could recognize other chromosomal markers of response or refractoriness to LEN besides del[5q] using FISH and SNP-A. For example, trisomy 13 as the sole cytogenetic abnormality was reported to be possible good prognostic factor to LEN therapy [33], but was not detected in our LEN cohort. Instead, we found gain of chromosome 8 material to be predictive of response to LEN, although we acknowledge that 5 out of those 6 patients received combined LEN/ AZA therapy $[34,35]$.

In addition to cytogenetic abnormalities, we also studied mutational status of a variety of genes as possible markers of response. For example, ASXL1 mutations in CMML [36] and DNMT3A in AML [27] were reported to be poor prognostic factors. We identified 2 patients with DNMT3A mutations in our cohort, both of them achieved CR with LEN or LEN/AZA therapy.

This cohort used in this study has several limitations, including a limited size and the inclusion of patients with heterogenous disease entities. But, we have been able to demonstrate that a normal karyotype and gain of chromosome 8 material was predictive of response to LEN, while additional testing by FISH or SNP-A is not useful for better prediction of response in non-del[5q] patients with myeloid malignancies.

\section{Acknowledgements}

This work was supported by in part by R01HL-082983, K24 HL-077522, and grants from AA\&MDS International Foundation and Robert Duggan Charitable Fund (J.P.M).

\section{Author details}

${ }^{1}$ Department of Translational Hematology and Oncology Research, Cleveland Clinic Taussig Cancer Institute, Cleveland, OH, USA. ${ }^{2}$ Hematologic Oncology and Blood Disorders, Cleveland Clinic Taussig Cancer Institute, Cleveland, $\mathrm{OH}$, USA. ${ }^{3} \mathrm{H}$. Lee Moffitt Cancer Center, Tampa, FL, USA. ${ }^{4}$ Translational Hematology and Oncology Research, Taussig Cancer Institute R-40, Cleveland Clinic, 9500 Euclid Ave, Cleveland, OH, USA.

\section{Authors' contributions}

YS and JPM designed research, performed research, analyzed data, and wrote the paper. HM, FT, W, AJ, AJ, HS, CLO, KG performed research. MA, RT, KRM and AFL analyzed data. All authors read and approved the final manuscript.

\section{Competing interests}

The authors declare that they have no competing interests.

Received: 11 January 2012 Accepted: 5 March 2012

Published: 5 March 2012

\section{References}

1. List A, Kurtin S, Roe DJ, Buresh A, Mahadevan D, Fuchs D, et al: Efficacy of lenalidomide in myelodysplastic syndromes. N Engl J Med 2005, 352:549-57.

2. List A, Dewald G, Bennett J, Giagounidis A, Raza A, Feldman E, et al: Myelodysplastic syndrome-003 study investigators. Lenalidomide in the myelodysplastic syndrome with chromosome $5 q$ deletion. $N$ Engl J Med 2006, 355:1456-65

3. Adès L, Boehrer S, Prebet T, Beyne-Rauzy O, Legros L, Ravoet C, et al: Efficacy and safety of lenalidomide in intermediate- 2 or high-risk myelodysplastic syndromes with $5 q$ deletion: results of a phase 2 study. Blood 2009, 113:3947-52.

4. Raza A, Reeves JA, Feldman EJ, Dewald GW, Bennett JM, Deeg HJ, et al: Phase 2 study of lenalidomide in transfusion-dependent, low-risk, and intermediate-1-risk myelodysplastic syndromes with karyotypes other than deletion 5q. Blood 2008, 111:86-93.

5. Fehniger TA, Uy GL, Trinkaus K, Nelson AD, Demland J, Abboud CN, et al: A phase II study of high dose lenalidomide as initial therapy for older patients with acute myeloid leukemia. Blood 2011, 117:1828-33.

6. Sekeres MA, Gundacker H, Lancet J, Advani A, Petersdorf S, Liesveld JL, et al: A phase II study of lenalidomide for previously untreated deletion (del) $5 q$ acute myeloid leukemia (AML) patients age 60 or older who are not candidates for remission induction chemotherapy (Southwest Oncology Group Study S0605). Blood 2010, 116:150.

7. Kulasekararaj AG, Mohamedali AM, Smith AE, Lea NC, Kizilors A, Abdallah A, et al: Polycomb complex group gene mutations and their prognostic relevance In 5-azacitidine treated myelodysplastic syndrome patients. Blood 2010, 116:61.

8. Jädersten M, Saft L, Smith A, Kulasekararaj A, Pomplun S, Göhring G, et al: TP53 mutations in low-risk myelodysplastic syndromes with del(5q) predict disease progression. J Clin Oncol 2011, 29:1971-9.

9. Möllgård L, Saft L, Treppendahl MB, Dybedal I, Nørgaard JM, Astermark J, et al: Clinical effect of increasing doses of lenalidomide in high-risk myelodysplastic syndrome and acute myeloid leukemia with chromosome 5 abnormalities. Haematologica 2011, 96:963-971. 
10. Makishima H, Rataul M, Gondek LP, Huh J, Cook JR, et al: FISH and SNP-A karyotyping in myelodysplastic syndromes: improving cytogenetic detection of $\operatorname{del}(5 q)$, monosomy 7 , del(7q), trisomy 8 and del(20q). Leuk Res 2009, 34:447-53.

11. Maciejewski JP, Mufti GJ: Whole genome scanning as a cytogenetic tool in hematologic malignancies. Blood 2008, 112:965-74.

12. Delhommeau F, Dupont S, Della Valle V, James C, Trannoy S, Massé A, Kosmider $\mathrm{O}$, et al: Mutation in TET2 in myeloid cancers. $N$ Engl J Med 2009, 360:2289-301.

13. Jankowska AM, Szpurka H, Tiu RV, Makishima H, Afable M, Huh J, et al: Loss of heterozygosity $4 \mathrm{q} 24$ and TET2 mutations associated with myelodysplastic/myeloproliferative neoplasms. Blood 2009, 113:6403-10.

14. Haaften G, Dalgliesh GL, Davies H, Chen L, Bignell G, Greenman C, et al: Somatic mutations of the histone H3K27 demethylase gene UTX in human cancer. Nat Genet 2009, 41:521-23.

15. Makishima H, Cazzolli H, Szpurka H, Dunbar A, Tiu R, Huh J, et al: Mutations of E3 ubiquitin ligase $\mathrm{Cbl}$ family members constitute a novel common pathogenic lesion in myeloid malignancies. J Clin Oncol 2009, 27:6109-16.

16. Nikoloski G, Langemeijer SM, Kuiper RP, Knops R, Massop M, Tönnissen ER, et al: Somatic mutations of the histone methyltransferase gene EZH2 in myelodysplastic syndromes. Nat Genet 2010, 42:665-7.

17. Ernst T, Chase AJ, Score J, Hidalgo-Curtis CE, Bryant C, Jones AV, et al: Inactivating mutations of the histone methyltransferase gene $\mathrm{EZH} 2$ in myeloid disorders. Nat Genet 2010, 42:722-6.

18. Makishima H, Jankowska AM, Tiu RV, Szpurka H, Sugimoto Y, Hu Z, et al: Novel homo- and hemizygous mutations in EZH2 in myeloid malignancies. Leukemia 2010, 24:1799-804.

19. Gelsi-Boyer V, Trouplin V, Adélaïde J, Bonansea J, Cervera N, Carbuccia N, et al: Mutations of polycomb-associated gene ASXL1 in myelodysplastic syndromes and chronic myelomonocytic leukaemia. Br J Haematol 2009, 145:788-800

20. Carbuccia N, Trouplin V, Gelsi-Boyer V, Murati A, Rocquain J, Adélaïde J, et al: Mutual exclusion of ASXL1 and NPM1 mutations in a series of acute myeloid leukemias. Leukemia 2010, 24:469-73.

21. Sugimoto $Y$, Muramatsu H, Makishima H, Prince C, Jankowska AM Yoshida $N$, et al: Spectrum of molecular defects in juvenile myelomonocytic leukaemia includes ASXL1 mutations. Br J Haematol 2010, 150:83-7.

22. Lai JL, Preudhomme C, Zandecki M, Flactif M, Vanrumbeke M, Lepelley P, et al: Myelodysplastic syndromes and acute myeloid leukemia with $17 p$ deletion. An entity characterized by specific dysgranulopoiesis and a high incidence of P53 mutations. Leukemia 1995, 9:370-81.

23. Jasek M, Gondek LP, Bejanyan N, Tiu R, Huh J, Theil KS, et al: TP53 mutations in myeloid malignancies are either homozygous or hemizygous due to copy number-neutral loss of heterozygosity or deletion of 17p. Leukemia 2010, 24:216-9.

24. Bos JL, Toksoz D, Marshall CJ, Verlaan-de Vries M, Veeneman GH, van der Eb AJ, et al: Amino acid substitutions at codon I 3 of the N-ras oncogene in human acute myeloid leukaemia. Nature 1985, 31:726-30.

25. Neri A, Knowles DM, Greco A, McCormick F, Dalla-Favera R: Analysis of RAS oncogene mutations in human lymphoid malignancies. Proc Natl Acad Sci USA 1988, 85:9268-72.

26. Marcucci G, Maharry K, Wu YZ, Radmacher MD, Mrózek K, Margeson D, et al: IDH1 and IDH2 gene mutations identify novel molecular subsets within de novo cytogenetically normal acute myeloid leukemia: a Cancer and Leukemia Group B study. J Clin Oncol 2010, 28:2348-55.

27. Ley TJ, Ding L, Walter MJ, McLellan MD, Lamprecht T, Larson DE, et al: DNMT3A mutations in acute myeloid leukemia. N Engl J Med 2010, 363:2424-33.

28. Cheson BD, Greenberg PL, Bennett JM, Lowenberg B, Wijermans PW, Nimer SD, et al: Clinical application and proposal for modification of the International Working Group (IWG) response criteria in myelodysplasia. Blood 2006, 108:419-25.

29. Shaffer LG, Tommerup N: ISCN 2005. An international system for human cytogenetics nomenclature Basel: Karger; 2005.

30. Mitani K, Hangaishi A, Imamura N, Miyagawa K, Ogawa S, Kanda Y, et al: No concomitant occurrence of the $\mathrm{N}$-ras and $\mathrm{p} 53$ gene mutations in myelodysplastic syndromes. Leukemia 1997, 11:863-5.

31. Mallo M, Arenillas L, Espinet B, Salido M, Hernández JM, Lumbreras E, et al: Fluorescence in situ hybridization improves the detection of $5 q 31$ deletion in myelodysplastic syndromes without cytogenetic evidence of 5q-. Haematologica 2008, 93:1001-8.

32. Nimer SD: Clinical management of myelodysplastic syndromes with interstitial deletion of chromosome 5q. J Clin Oncol 2006, 24:2576-82.

33. Fehniger TA, Byrd JC, Marcucci G, Abboud CN, Kefauver C, Payton JE, et al: Single-agent lenalidomide induces complete remission of acute myeloid leukemia in patients with isolated trisomy 13. Blood 2009, 113:1002-5.

34. Sekeres MA, List AF, Cuthbertson D, Paquette R, Ganetzky R, Latham D, et al: Phase I combination trial of lenalidomide and azacitidine in patients with higher-risk myelodysplastic syndromes. J Clin Oncol 2010, 28:2253-8.

35. Sekeres MA, O'Keefe C, List AF, Paulic K, Afable M II, Englehaupt R, et al: Demonstration of additional benefit in adding lenalidomide to azacitidine in patients with higher-risk myelodysplastic syndromes. Am J Hematol 2011, 86:102-3.

36. Gelsi-Boyer V, Trouplin V, Roquain J, Adélaïde J, Carbuccia N, Esterni B, et al: ASXL1 mutation is associated with poor prognosis and acute transformation in chronic myelomonocytic leukaemia. $\mathrm{Br} J$ Haematol 2010, 151:365-75.

doi:10.1186/1756-8722-5-4

Cite this article as: Sugimoto et al:: Cytogenetic and molecular predictors of response in patients with myeloid malignancies without del[5q] treated with lenalidomide. Journal of Hematology \& Oncology 2012 5:4.

\section{Submit your next manuscript to BioMed Central and take full advantage of:}

- Convenient online submission

- Thorough peer review

- No space constraints or color figure charges

- Immediate publication on acceptance

- Inclusion in PubMed, CAS, Scopus and Google Scholar

- Research which is freely available for redistribution

Submit your manuscript at www.biomedcentral.com/submit
C) Biomed Central 